\title{
Effect of thalidomide and rosiglitazone on the prevention of diabetic retinopathy in streptozotocin-induced diabetic rats
}

\author{
A. A. Bosco ${ }^{1,2}$ - A. C. Lerario $^{1}$ - R. F. Santos ${ }^{1}$ B. L. Wajchenberg ${ }^{1}$ \\ ${ }^{1}$ Endocrine Center Research of Santa Casa, Belo Horizonte and Laboratory of Medical Investigation of FMUSP (LIM 18), \\ Hospital das Clinicas University of São Paulo, São Paulo, Brazil \\ ${ }^{2}$ Rua Padre Rolin 515/801, Santa Efigênia-Belo Horizonte/MG, Brasil
}

\section{Diabetologia (2003) 46:1669-1675}

Due to an oversight by the authors, the following Acknowledgement was omitted:

"The authors would like to acknowledge the essential contributions made to this study by: M. J. M. Ursich, D. Marreiro-Rocha, M.E. Rossi da Silva, M. R. Soares, R. Fukui (all FMUSP Sao Paulo, Brazil) and P. Massote (Belo Horizonte, Brazil), and would like to thank them for their important work."
Published online: 5 May 2004

(C) Springer-Verlag 2004

DOI 10.1007/s00125-004-1377-8

The online version of the original article can be found at http://dx.doi.org/10.1007/s00125-003-1234-1

Dr. A. A. Bosco (๘)

Rua Padre Rolin 515/801,

CEP-30130-090 Santa Efigênia-Belo Horizonte/MG, Brasil

E-mail: a.bosco@terra.com.br 